\title{
Design of a Coupler with Three Reconfigurable Output Ports and a Beamwidth Reconfigurable Antenna
}

\author{
Dong-Woo Kim and Soon-Soo Oh \\ Electronic Engineering, Chosun University, 309 Pilmundae-ro, Dong-gu, Gwangju 61452, Republic of Korea \\ Correspondence should be addressed to Soon-Soo Oh; ssoh@chosun.ac.kr
}

Received 19 November 2016; Revised 8 January 2017; Accepted 30 January 2017; Published 6 April 2017

Academic Editor: Jaume Anguera

Copyright (c) 2017 Dong-Woo Kim and Soon-Soo Oh. This is an open access article distributed under the Creative Commons Attribution License, which permits unrestricted use, distribution, and reproduction in any medium, provided the original work is properly cited.

\begin{abstract}
The design and fabrication of a coupler with three reconfigurable output ports have been proposed. The output ports of the proposed coupler can be adjusted by varying the number of shorting pins. An antenna with a reconfigurable beamwidth has been also involved in this paper. The proposed antenna has a coupler and a $1 \times 3$ array rectangular patch. The beamwidth is set by the number of output ports. The simulation and experiment show the verification of the proposed coupler and beamwidth variation of array antenna. The broadest measured beamwidth was $66.2^{\circ}$ and the sharpest measured beamwidth was $24.1^{\circ}$.
\end{abstract}

\section{Introduction}

Recently, many wireless communication devices have been produced with the growth and development of the information industry. The technology for detecting the position of a vehicle using radiofrequency identification (RFID) has utilized a reconfigurable beamwidth antenna [1]. The construction of an inexpensive high-efficiency system using RFID technology in the railway environment has been proposed [1-4]. The design reconfigures the beamwidth based on the speed of the vehicle and tags on the railway [4]. The technique of beamwidth reconfiguration could be also utilized for wireless communications for fast data transferring. Previously, the beamwidth configuration has been implemented by turning on/off the diode installed on the partially reflective surface (PRS) [5]. The diode could be replaced with microelectromechanical system (MEMS) [6]. The antenna effective size was adjusted by tuning the varactor installed in the parasitic patch, resulting in a beamwidth reconfiguration [7].

This paper presents a novel antenna with a triple-mode beamwidth using a $1 \times 3$ array. The beamwidth of the antenna can be reconfigured using a branch hybrid coupler, due to the triple mode of the antenna. According to array antenna theory, when the number of radiated elements increases, the directivity increases and the beamwidth becomes sharper in the direction of radiation [8]. Conversely, when the number of radiated elements decreases, the directivity decreases and the beamwidth becomes broader [8]. It is possible to adjust the number of branches delivering power by inserting shorting pins into the shunt arms of the coupler [9-12]. A ratrace coupler was utilized in $[9,10]$ by adjusting the impedance of even- and odd-mode, while the power divider was used in [11] by optimizing the line width. They worked very well, but the output port is two-way.

In this paper, the three-way coupler has been proposed, and even coupler can split the power one, two, or three ways. The split power is input to the antenna from the output port of the coupler. The proposed system was simulated using a twodimensional (2D) electromagnetic (EM) simulator (ANSYS Designer).

\section{Coupler with Three Reconfigurable Output Ports}

A coupler with three output ports was designed for a reconfigurable beamwidth antenna. The construction of the designed coupler was combined with two quadrature hybrid couplers [13], as shown in Figure 1. This was simulated using the EM simulator. Port 1 is the input port; ports 2, 3, and 4 are the output ports; and ports 5 and 6 are isolated ports. The center frequency of this coupler is $915 \mathrm{MHz}$, the substrate is $1.6 \mathrm{~mm}$ 


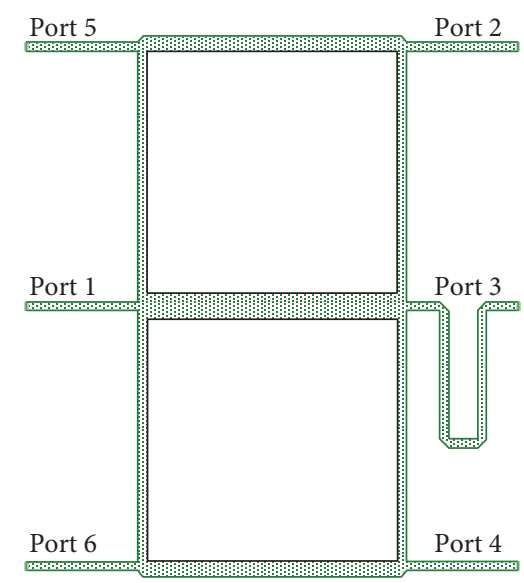

(a)

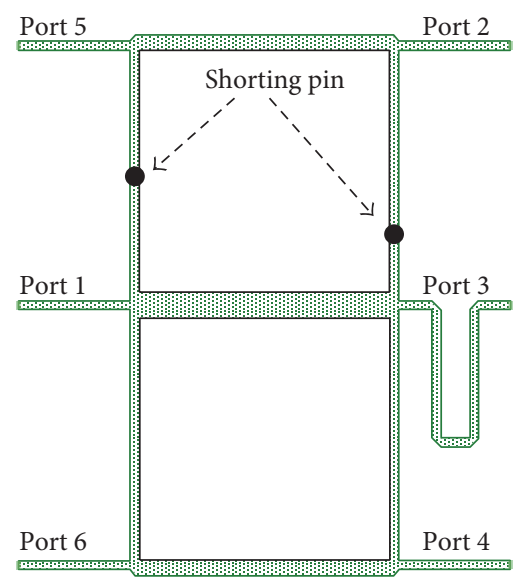

(b)

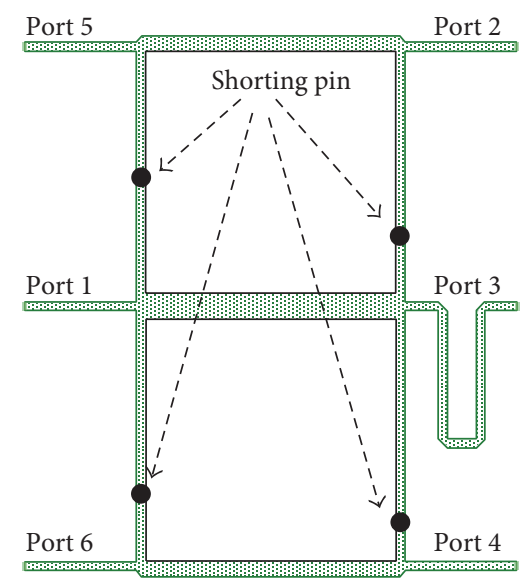

(c)

FIGURE 1: The couplers designed with (a) 0 , (b) 2, and (c) 4 shorting pins.

thick, the permittivity is 4.4 , and the loss tangent is 0.02 . The length and width of the feeding line were optimized at onequarter wavelength $(\lambda / 4)$ and $2 \mathrm{~mm}$, respectively, yielding the appropriate power ratio at $915 \mathrm{MHz}$. A $\lambda / 4$ length was added at port 3 , so that ports 2 and 4 would be in phase.

This paper simulates three cases, with 0,2 , or 4 shorting pins. In the case without shorting pins, the power is split to the three output ports. In the case with two shorting pins, the power passes to ports 3 and 4 because of the shorting pins in the shunt arm to port 2. Similarly, the power in the case with four shorting pins converges on port 3 because of the shorting pins in the shunt arms of ports 2 and 4.

Figure 2 shows the surface current distribution of the designed couplers at $915 \mathrm{MHz}$. As shown in Figure 2(a), the current in the case without shorting pins is split equally among the three output ports. In the case with two shorting pins, the current is split equally between ports 3 and 4 because the current to port 2 is blocked (Figure 2(b)). In the case with four shorting pins, the current flows only to port 3 because the current passes to the ground in all of the shunt arms due to the four shorting pins (Figure 2(c)). As a result, the current in the three cases can be divided and blocked by turning the shorting pins on and off.

As shown in Figure 3, a prototype coupler was fabricated using a photoetching method on a dielectric substrate with a relative permittivity of 4.4 , a loss tangent of 0.02 , and a thickness of $1.6 \mathrm{~mm}$. The SMA connector was soldered to a feeding line with an impedance of $50 \Omega$. Shorting pins were fabricated to connect the copper in the top and bottom layers. The fabricated couplers measured $84.5 \times 110 \mathrm{~mm}^{2}$.

The graphs in Figure 4 compare the simulated $S$ parameter and that measured using a Keysight E5063A ENA series network analyzer. The $S$-parameter was measured for four ports in the three types of coupler. For accurate measurement, the isolated ports 5 and 6 were terminated. As shown in the graphs, the measured $S_{11}$ is less than $-10 \mathrm{~dB}$ at $915 \mathrm{MHz}$. From Figure 4(a), the measured values of $S_{21}$,
$S_{31}$, and $S_{41}$ were about $-5 \mathrm{~dB}$ at $915 \mathrm{MHz}$, indicating that the power is split equally to the three output ports. This is similar to the simulation result. From Figure $4(\mathrm{~b}), S_{21}$ is $-36 \mathrm{~dB}, S_{31}$ is $-5 \mathrm{~dB}$, and $S_{41}$ is $-3 \mathrm{~dB}$. This shows that the power passes to ports 3 and 4 and not to port 2. Compared with the simulation result, the measured values of $S_{31}$ and $S_{41}$ differ by $1 \mathrm{~dB}$.

\section{Variable Beamwidth of a $1 \times 3$ Array Antenna}

Figure 5 presents the reconfigurable system beamwidth simulated using ANSYS Designer. The antenna is a $1 \times 3$ rectangular patch array etched on substrate with a relative permittivity of 2.2 and a thickness of $1.6 \mathrm{~mm}$. The patch measures $170 \times$ $108 \mathrm{~mm}^{2}$. Quarter-wave transformer technology is used to match the impedance between the antenna port and radiated element [13]. Three single antennas are arranged in the $\mathrm{H}$ plane. The radiated elements and output ports of the coupler are connected by a $50 \Omega$ coaxial cable. Each input source of the radiated element is entered using the extracted $S$ parameter of the amplitude and the phase at the output ports of the coupler.

Figure 6 shows the entire prototype beamwidth reconfigurable antenna. As in the prototype, to facilitate measurements, it is coupled with a zigzag section. The designed reconfigurable beamwidth system consists of the rectangular patch and coupler. The input of the antenna and output of the coupler are connected using a semirigid coaxial cable. The lengths of the three cables are the same so that they are in phase. The isolated ports 5 and 6 are terminated to allow accurate measurement of the radiation pattern.

Figure 7 shows the radiation pattern in the $\mathrm{H}$-plane for the three cases at $915 \mathrm{MHz}$. Figure 7(a) shows the narrow beamwidth: the maximum gain is $11.3 \mathrm{dBi}$ and half bandwidth (HBW) is $24.1^{\circ}$. Figure 7 (b) shows the intermediate beamwidth: the maximum gain is $9.38 \mathrm{dBi}$ and $\mathrm{HBW}$ is $38^{\circ}$. The radiated beam is tilted at $13^{\circ}$ because port 2 of the coupler is blocked. Figure 7(c) shows the broad beamwidth: 


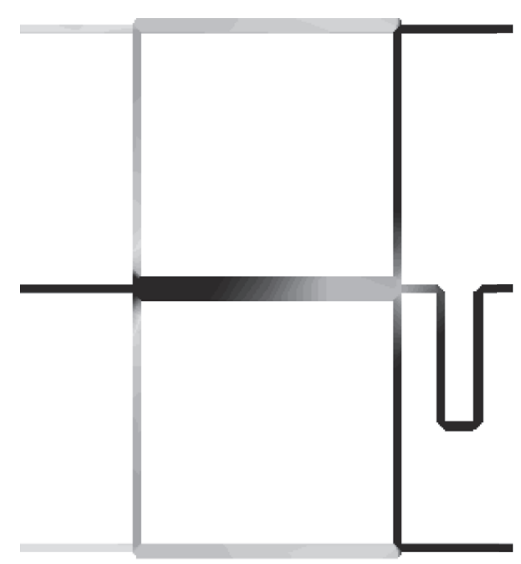

(a)
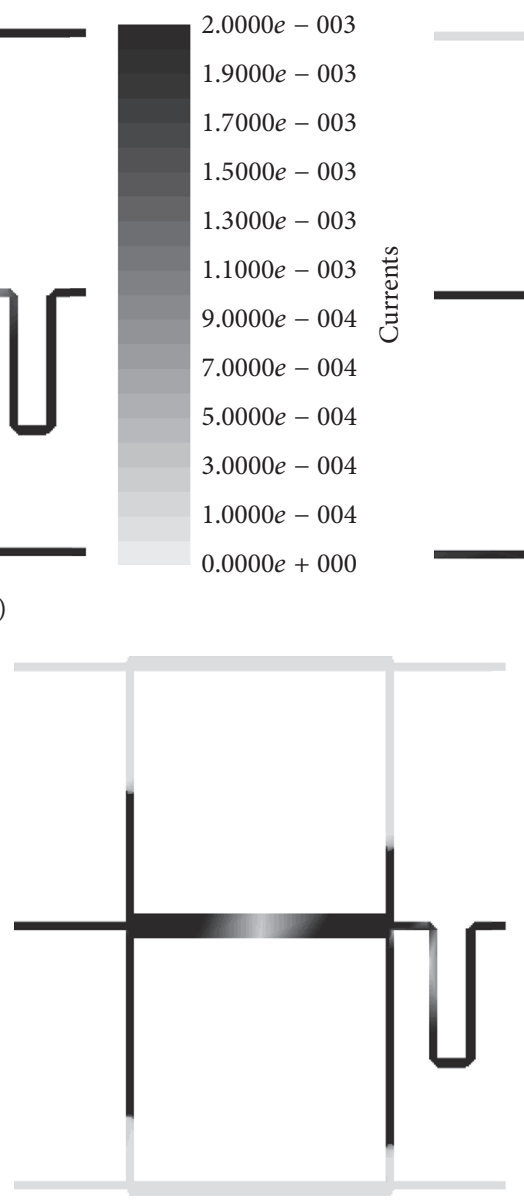

(c)

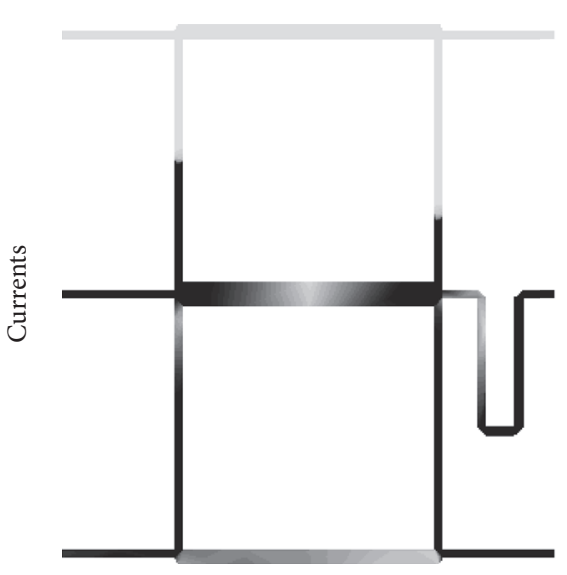

(b)
$2.0000 e-003$

$1.9000 e-003$

$1.7000 e-003$

$1.5000 e-003$

$1.3000 e-003$

$1.1000 e-003$

$9.0000 e-004$

$7.0000 e-004$

$5.0000 e-004$

$3.0000 e-004$

$1.0000 e-004$

$0.0000 e+000$

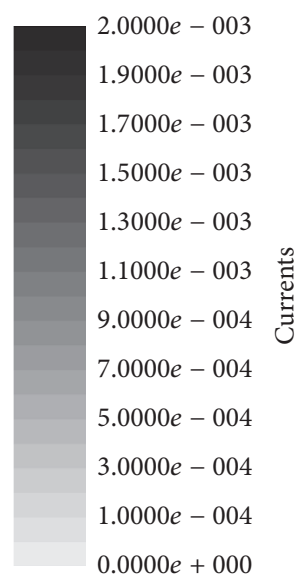

苞 

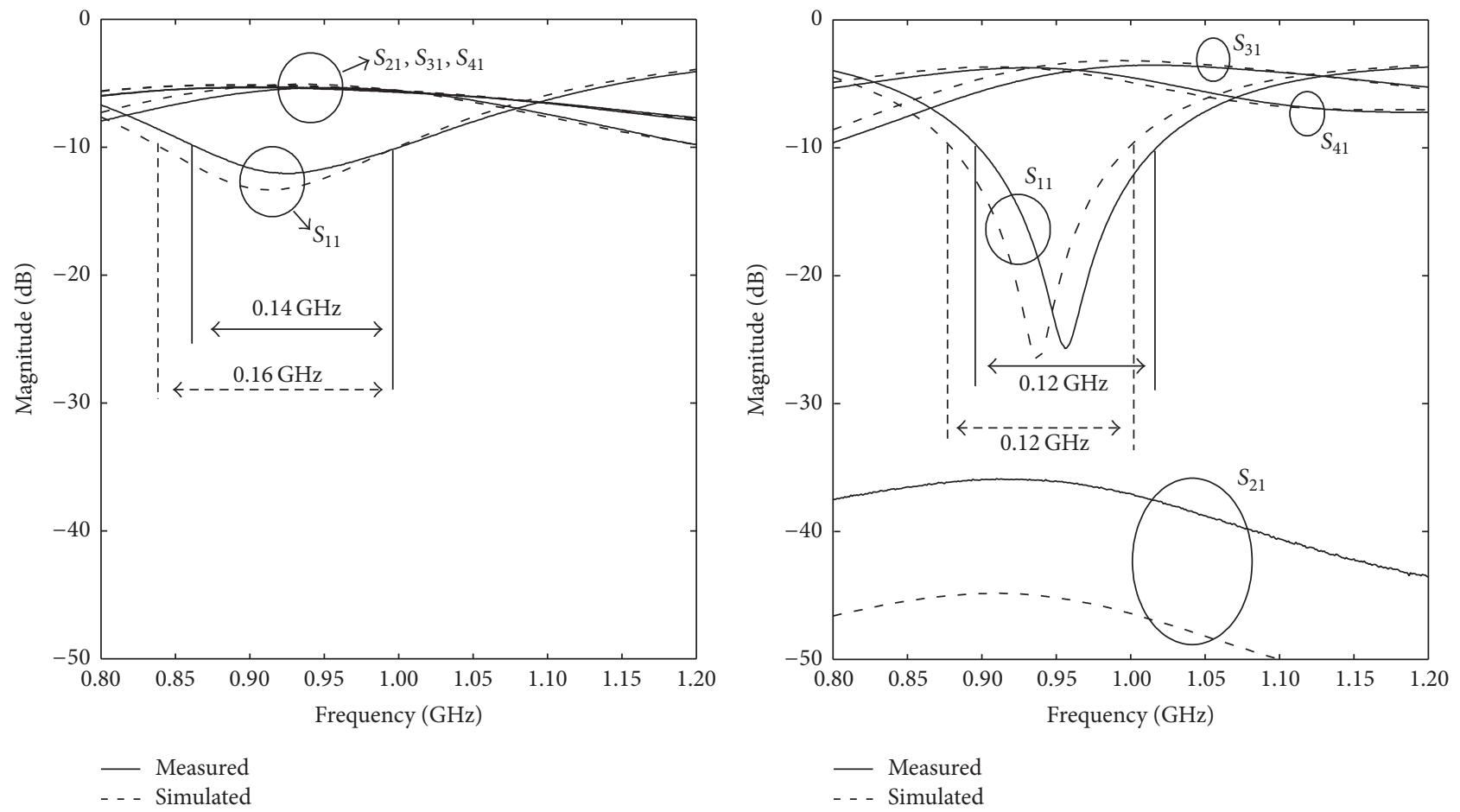

(a)

- . - Simulated

(b)

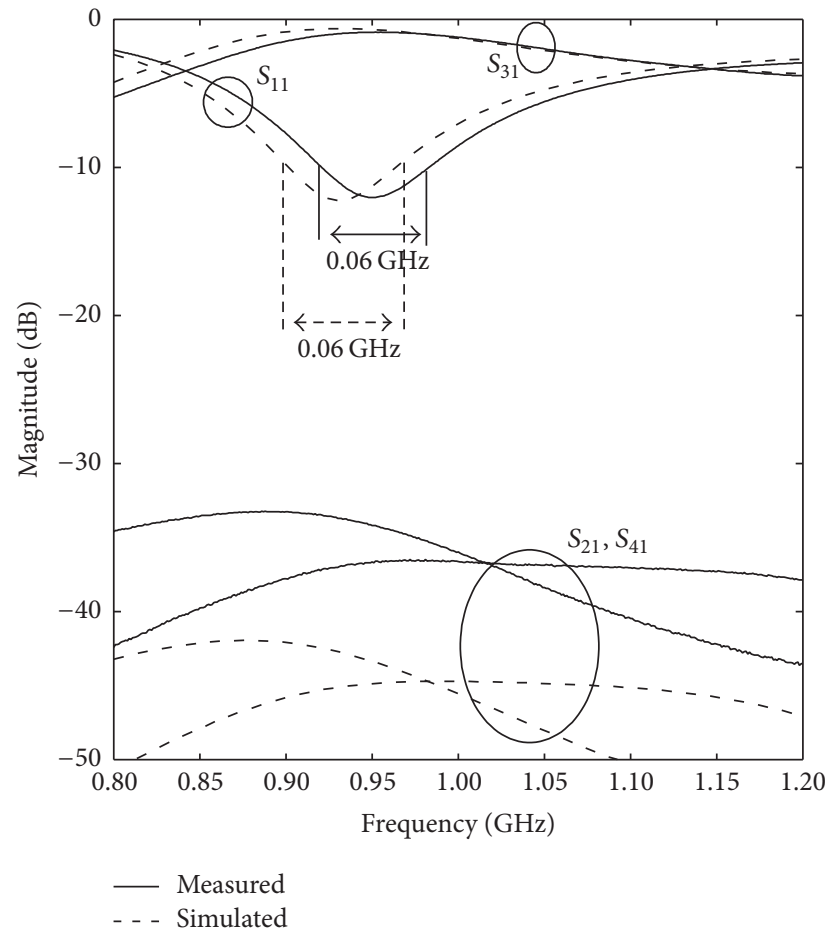

(c)

FIGURE 4: Simulated and measured results with (a) 0 , (b) 2, and (c) 4 shorting pins. 


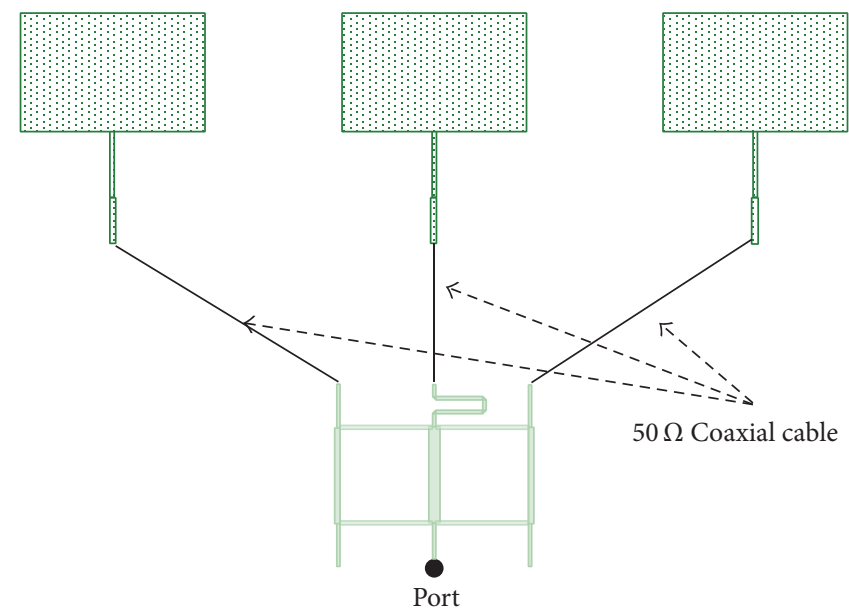

Figure 5: The combination $1 \times 3$ array antenna and coupler.

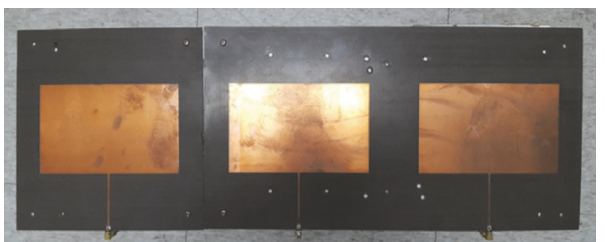

(a)

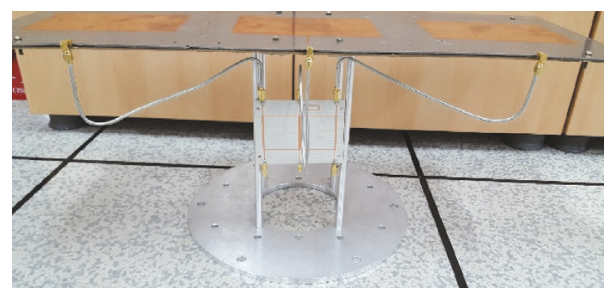

(b)

FiguRE 6: Fabricated beamwidth reconfigurable antenna: (a) top and (b) side views.

the maximum gain is $7.43 \mathrm{dBi}, \mathrm{HBW}$ is $66.2^{\circ}$, and it has a half omnidirectional pattern like the radiation pattern of a single patch antenna. Because the power is focused on port 3 of the coupler, the array antenna has the characteristics of a single patch antenna.

In order to verify the proposed coupler additionally, the PIN diode and bias-T were utilized for switching between two statuses electrically. If the biasing circuit for each PIN diode is used, three statuses shown in Figure 7 could be implemented. Figure 8 shows the designed and fabricated coupler using PIN diode and bias-T. The shorting pin and transmission line shown in Figure 8 are connected using PIN diode, which are enabled by a DC (direct current) supplied by a battery of $1.5 \mathrm{~V}$. The bias-T of minicircuit was used to simultaneously apply the RF and DC.

Figure 9 shows the result of $S$-parameter when DC is off- and on-status. In the case that DC is on, $S_{21}$ and $S_{41}$ decreased to $-17 \mathrm{~dB}$ and $-13 \mathrm{~dB}$ compared to when $\mathrm{DC}$ is off, and the current concentrated on port 3 with $S_{31}$ of $-1 \mathrm{~dB}$. The reason of concentration is that DC enabled PIN diodes to be active and, thus, shorted the branch arms. This phenomenon is similar to that shown in Figure 4 using 4 shorting pins.

The fabricated coupler was connected to the antenna as shown in Figure 6, and the radiation pattern was measured. Figure 10 shows the measured radiation pattern. When DC is off, the beamwidth decreased compared with the beamwidth of DC on-status.

The coupler shown in Figure 8 is for two switching statuses, and its performance was proved very well in Figures 9 and 10. Even though the characteristics of three statuses were verified as shown in Figures 1-4, but the coupler switching status was changed manually. If one want to change it fully electrically, the schematic diagram as shown in Figure 11 could be utilized, or the similar feeding method could be 

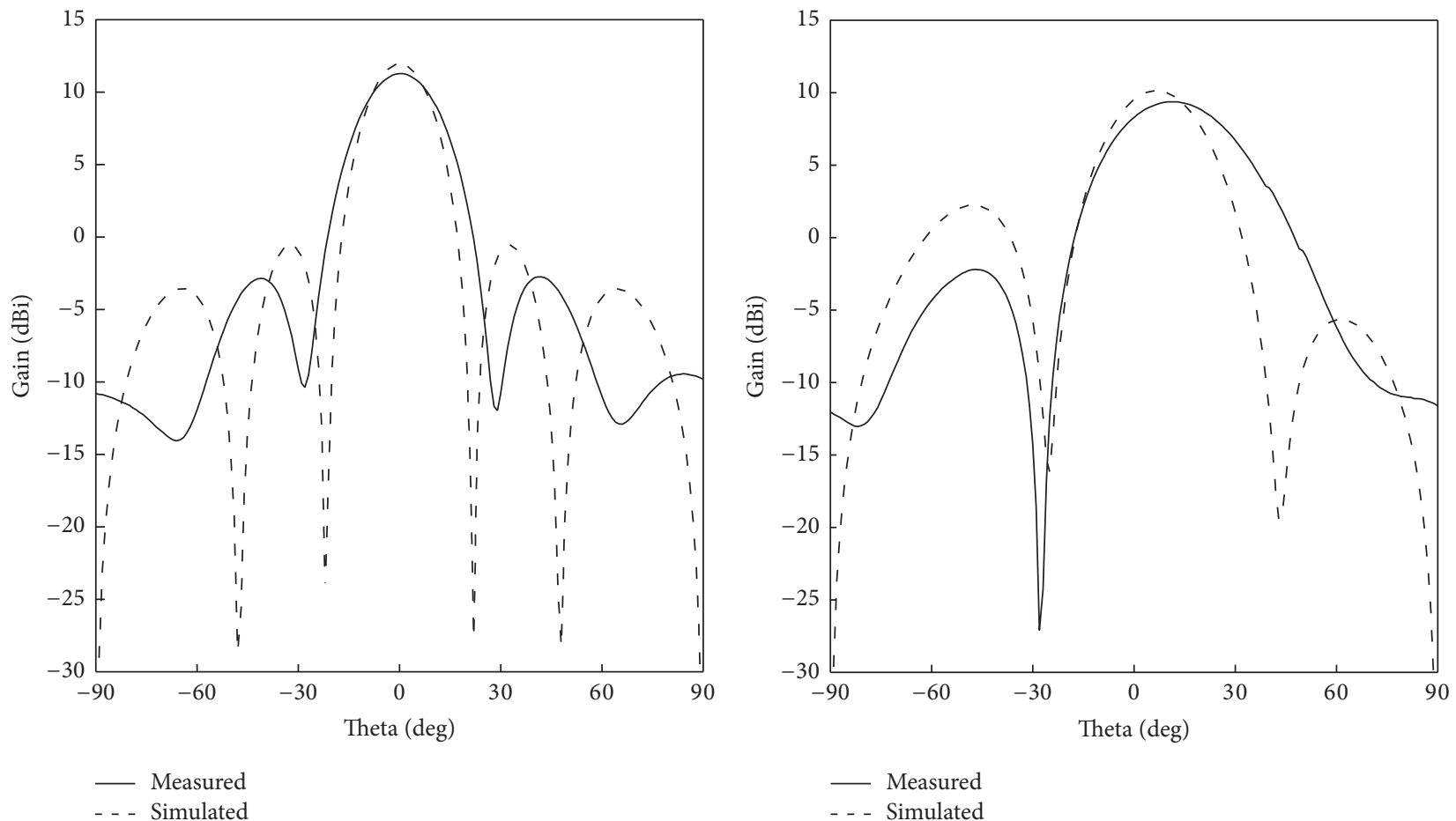

(a)

(b)

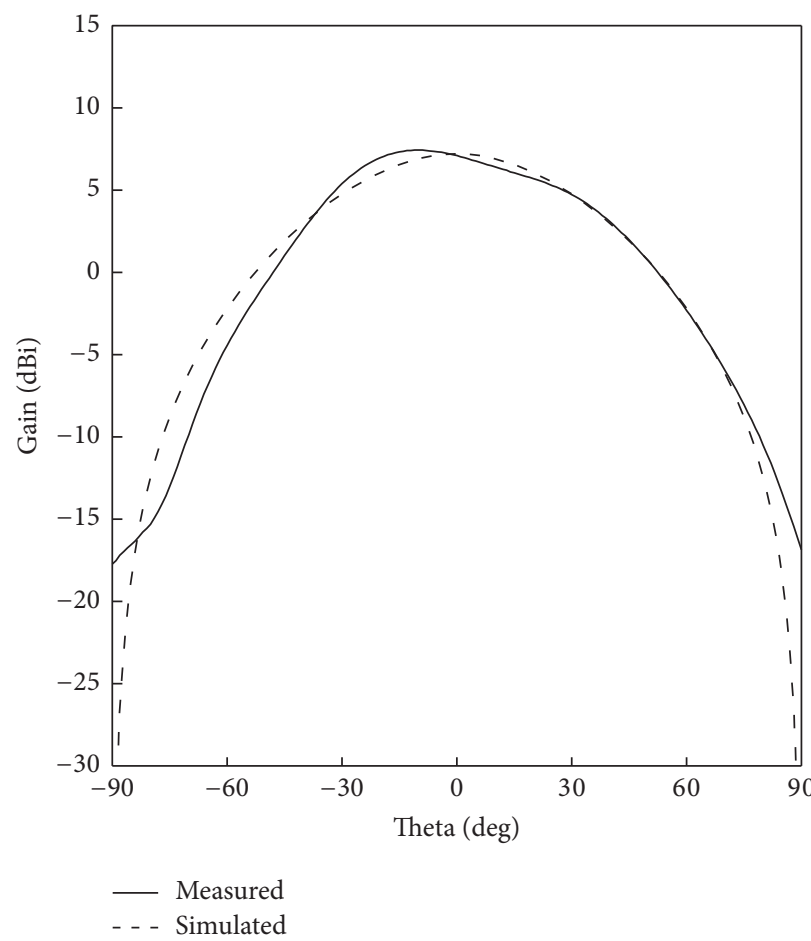

(c)

FIGURE 7: Measured radiation pattern with (a) 0, (b) 2, and (c) 4 shorting pins. 


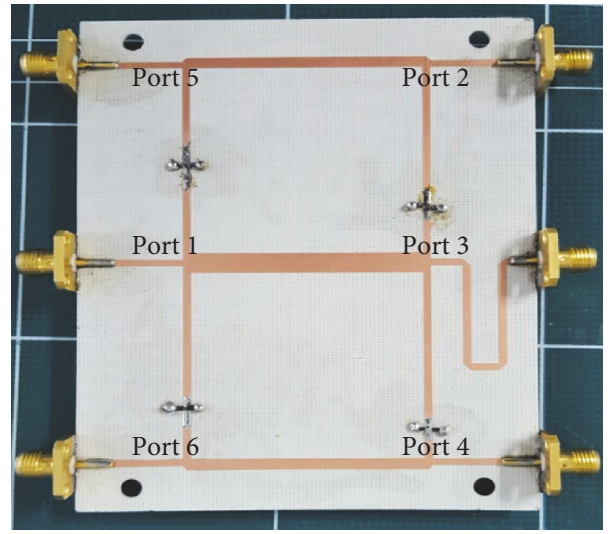

FIGURE 8: Prototypes of the coupler using PIN diode and bias-T.

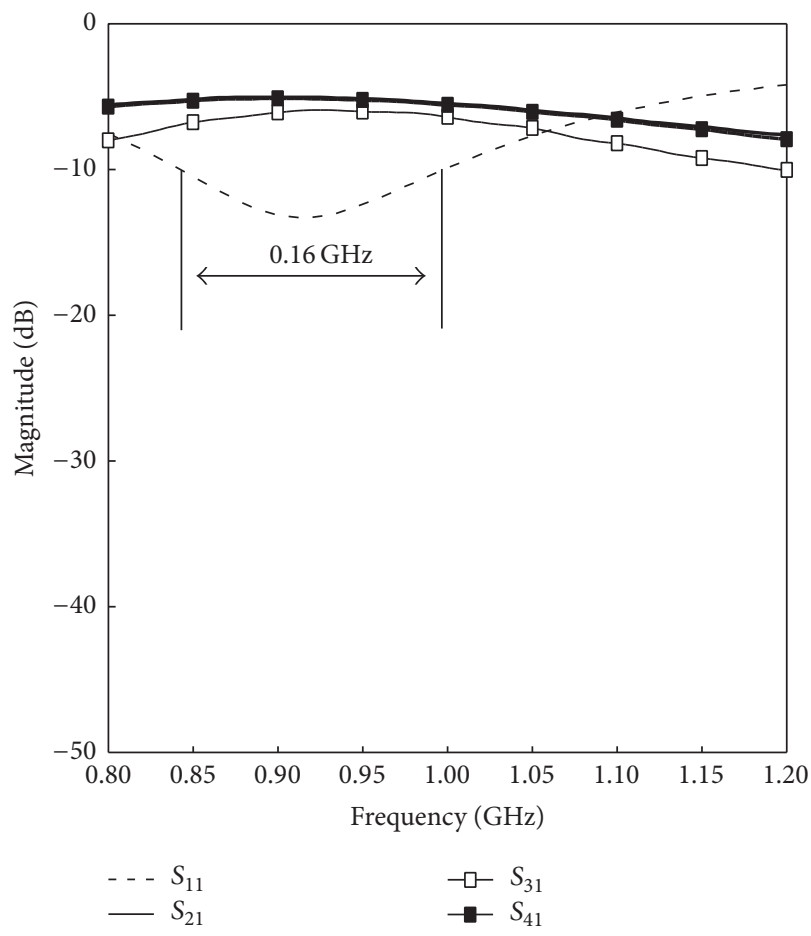

(a)

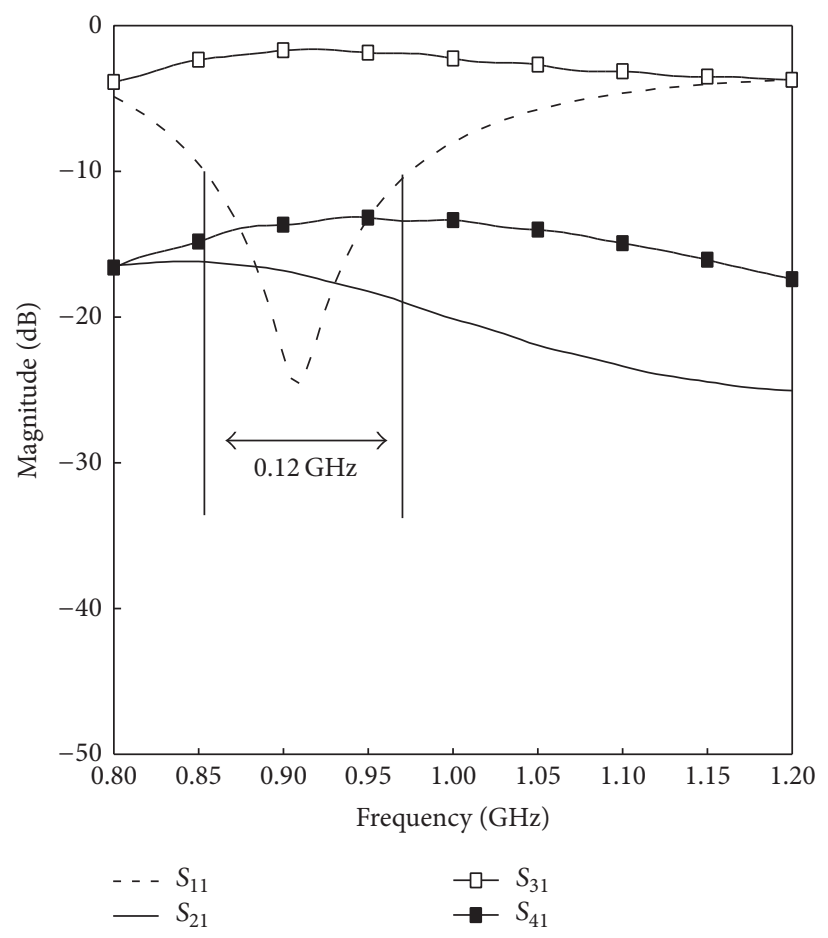

(b)

FIGURE 9: Measured S-parameter result of the coupler using PIN diode and bias-T: (a) DC off and (b) DC on.

found in $[14,15]$. The PIN diode is placed between the coupler branch and the pad connected to ground plate. The activation of PIN diode is done through DC bias line and RF choke. Generally, the high-value inductor, coil, or stub is used for $\mathrm{RF}$ choke. In order to block the DC flowing to RF port, the DC-blocking capacitor is placed between the coupler branches.

\section{Conclusion}

This study involved designing and fabricating a reconfigurable three-way coupler and its application to beamwidth reconfigurable antenna. It uses a $1 \times 3$ array antenna to radiate the different beamwidths; therefore, a coupler with three output ports was proposed. The proposed coupler can adjust the number of output ports by using shorting pins. The simulations and measurements demonstrated that the proposed coupler can adjust the number of active branches and the active radiating element to reconfigure the beamwidth of array antenna. The shoring pin, at first, was used for three switching statuses and then, the PIN diode was utilized with bias-T for two statuses. Finally the schematic of circuit is described for three switching statuses. The proposed coupler could be utilized for varying the antenna beamwidth in many communication applications such as detecting system of a vehicle, smart antenna system, and 5G wireless service. 


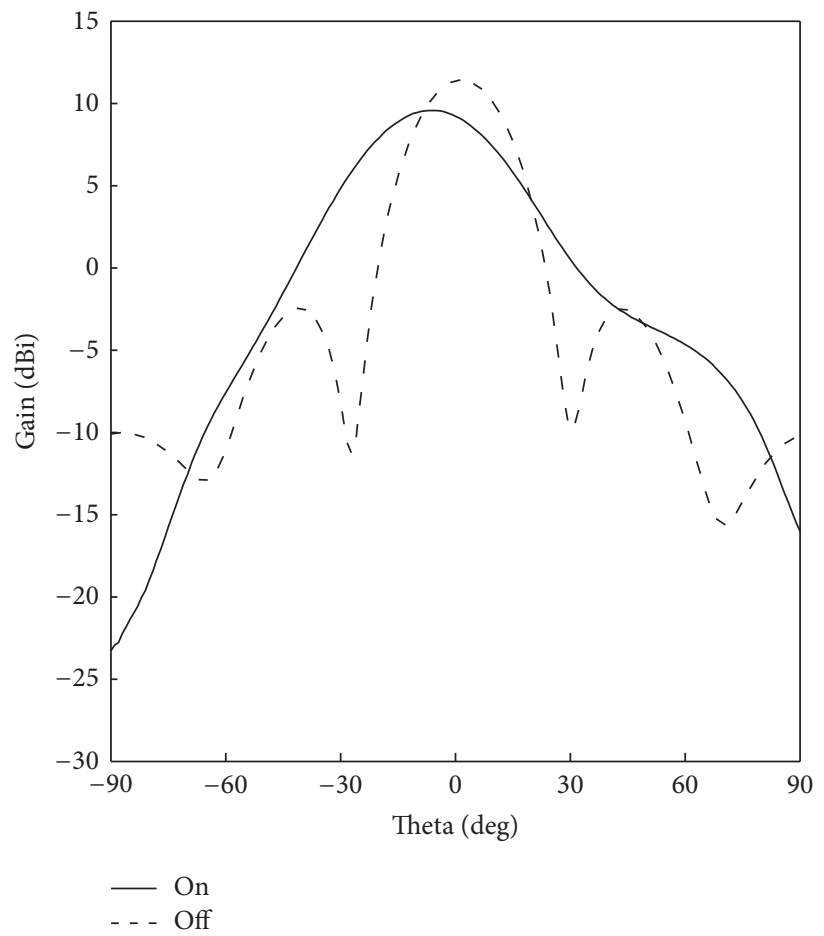

FIGURE 10: Measured radiation pattern of coupler using PIN diode and bias-T.

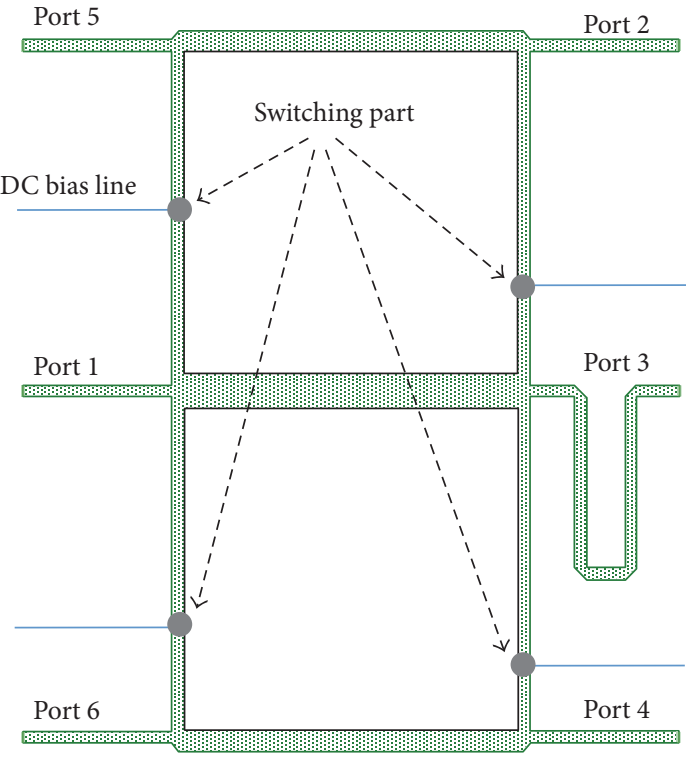

(a)

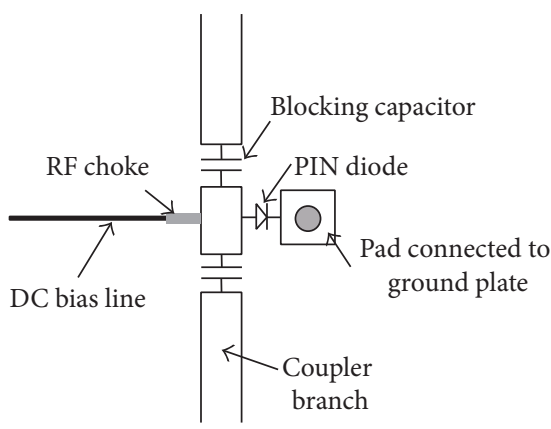

(b)

FIGURE 11: Schematic diagram of coupler using PIN diode and DC bias line: (a) whole structure and (b) switching part with PIN diode.

\section{Conflicts of Interest}

The authors declare that they have no conflicts of interest.

\section{Acknowledgments}

This research was supported by a grant from the Advanced Technology Center R\&D Program funded by the Ministry of Trade, Industry \& Energy of Korea (10048475), and this research was supported by research fund from Chosun University in Korea, 2016. The authors thank Dr. Gye-Taek Jeong and Dr. Jong-Chul Park for providing guidance on RF switching.

\section{References}

[1] C. H. Ahn, B. K. Cho, and J.-H. Kim, "Beam-width condition of RFID reader antenna for train location detection," in 
Proceedings of the Summer Conference of the Korean Institute of Electromagnetic Engineering and Science, p. 281, Jeju, South Korea, 2013.

[2] K. H. Shin and J. H. Lee, "Position detection technology in railway transportation," Journal of the Korean Society for Railway, vol. 15, pp. 16-21, 2012.

[3] B.-K. Cho, H.-C. Hwang, J.-H. Kim, and S.-H. Ryu, "RFID system response test for position detection of $420 \mathrm{~km} / \mathrm{h}$ highspeed train," in Proceedings of the International Conference on Information and Communication Technology Convergence, (ICTC '13), pp. 972-973, Jeju, Korea, October 2013.

[4] B. K. Cho, "RFID antenna for position detection of train," in Future Information Technology, vol. 309 of Lecture Notes in Electrical Engineering, pp. 903-908, Springer, Berlin, Germany, 2014.

[5] T. Debogovic, J. Perruisseau-Carrier, and J. Bartolic, "Partially reflective surface antenna with dynamic beamwidth control," IEEE Antennas and Wireless Propagation Letters, vol. 9, pp. 11571160, 2010.

[6] T. Debogović, J. Bartolić, and J. Perruisseau-Carrier, "Dualpolarized partially reflective surface antenna with MEMS-based beamwidth reconfiguration," IEEE Transactions on Antennas and Propagation, vol. 62, no. 1, pp. 228-236, 2014.

[7] A. Khidre, F. Yang, and A. Z. Elsherbeni, "Reconfigurable microstrip antenna with tunable radiation beamwidth," in Proceedings of the IEEE Antennas and Propagation Society International Symposium (APSURSI '13), pp. 1444-1445, Orlando, Fla, USA, July 2013.

[8] C. A. Balanis, Antenna Theory Analysis and Design, John Wiley \& Sons, New York, NY, USA, 3rd edition, 2005.

[9] K.-K. M. Cheng and S. Yeung, "A novel rat-race coupler with tunable power dividing ratio, ideal port isolation, and return loss performance," IEEE Transactions on Microwave Theory and Techniques, vol. 61, no. 1, pp. 55-60, 2013.

[10] K.-K. M. Cheng and M.-C. J. Chik, "A frequency-compensated rat-race coupler with wide bandwidth and tunable power dividing ratio," IEEE Transactions on Microwave Theory and Techniques, vol. 61, no. 8, pp. 2841-2847, 2013.

[11] B. Xia, L.-S. Wu, S.-W. Ren, and J.-F. Mao, "A balanced-tobalanced power divider with arbitrary power division," IEEE Transactions on Microwave Theory and Techniques, vol. 61, no. 8, pp. 2831-2840, 2013.

[12] K. Jang, S. Kahng, J. Jeon, and J. Anguera, "Small dual-band 3way metamaterial power-divider with the phase-compensated outputs," in Proceedings of the 44th European Microwave Conference (EuMC '14), pp. 319-322, Rome, Italy, October 2014.

[13] D. M. Pozar, Microwave Engineering, John Wiley \& Sons, New York, NY, USA, 2012.

[14] L. Gong, R. Ramer, and K. Y. Chan, "Beam steering spiral antenna reconfigured by PIN diodes," International Journal of Microwave and Wireless Technologies, vol. 6, no. 6, pp. 619-627, 2014, Proceedings of the Mediterranean Microwave Symposium 2013.

[15] L. Gong, Y. Yang, K. Y. Chan, and R. Ramer, "RHCP patternreconfigurable spiral antenna biased with two DC signals," Microwave and Optical Technology Letters, vol. 56, no. 7, pp. 1636-1640, 2014. 


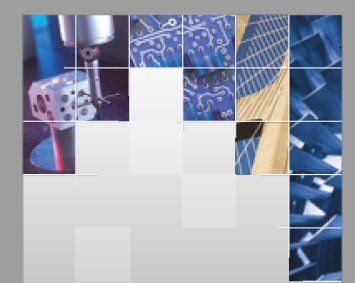

\section{Enfincering}
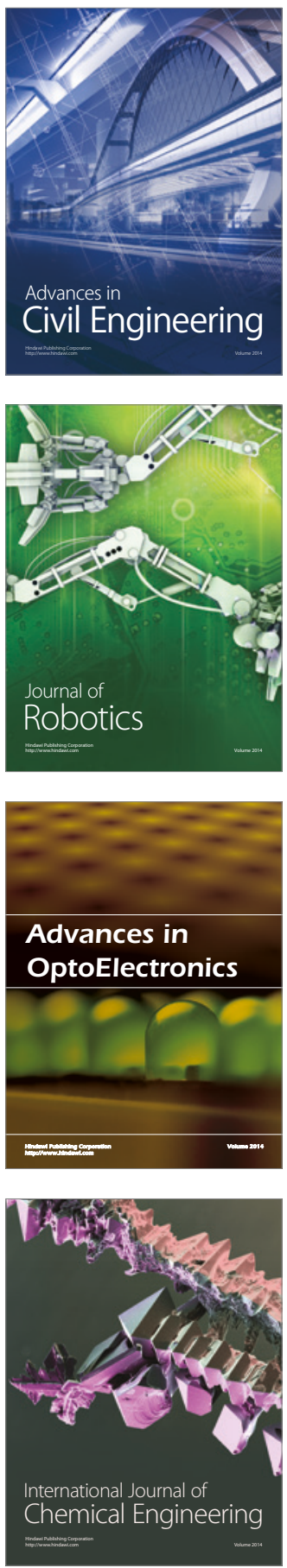

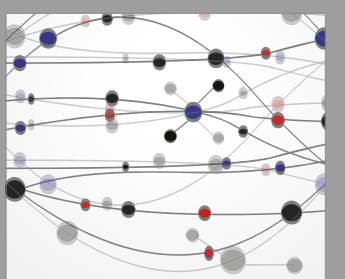

The Scientific World Journal

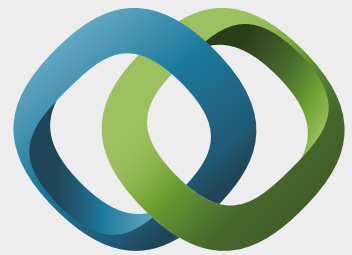

\section{Hindawi}

Submit your manuscripts at

https://www.hindawi.com
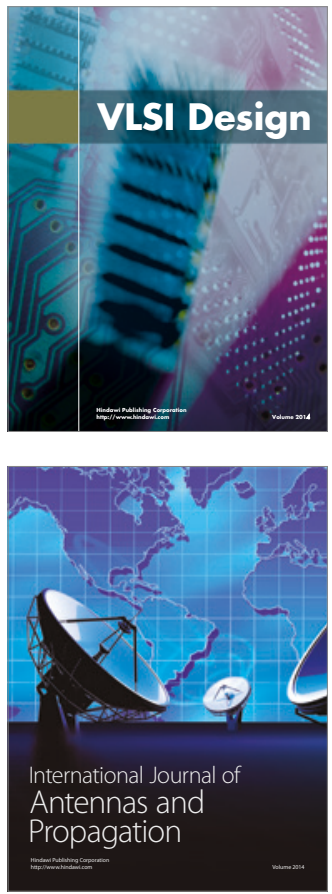

\section{Rotating}

Machinery
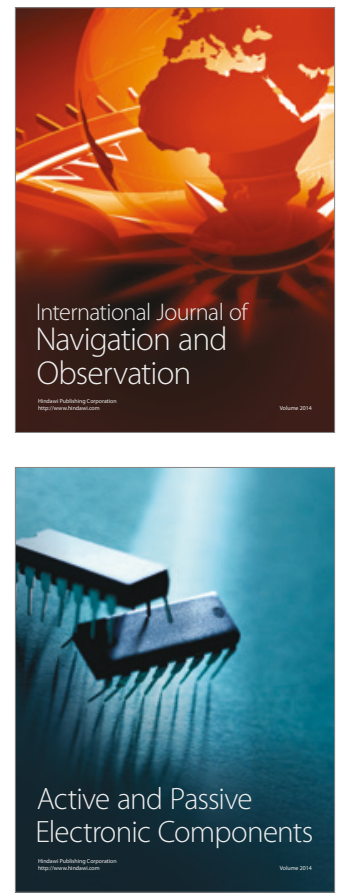
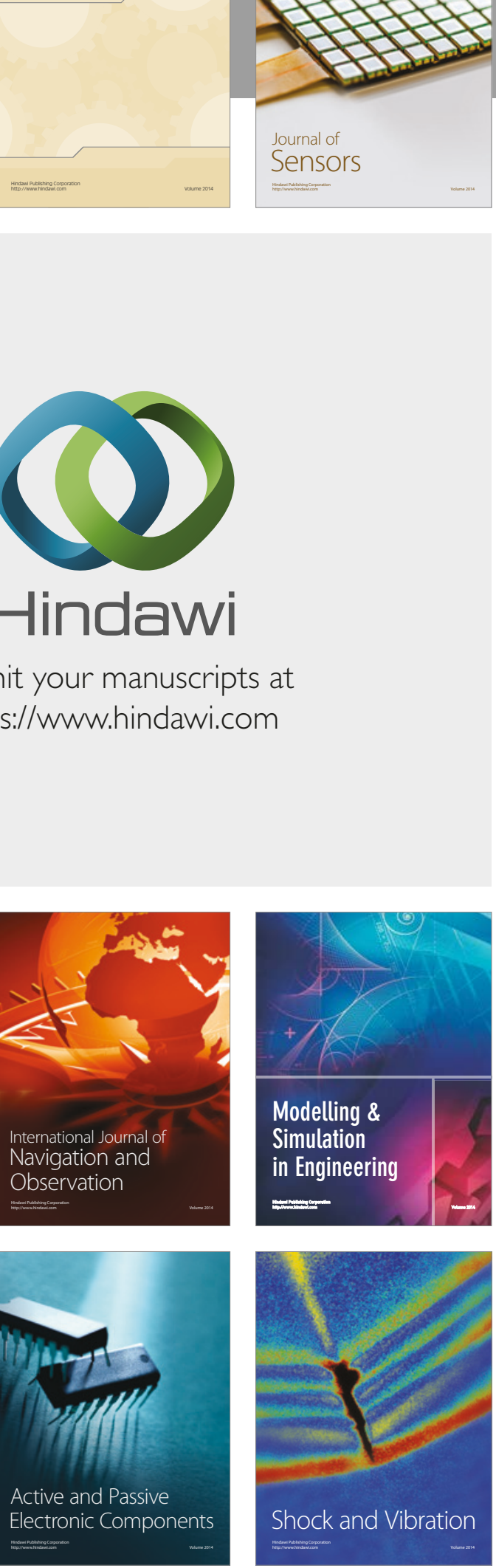
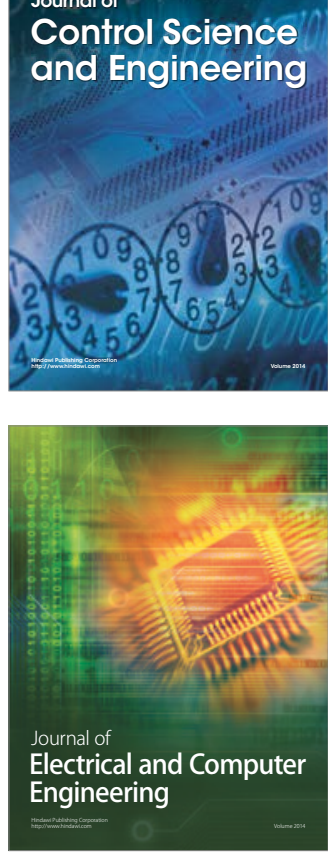

Distributed

Journal of

Control Science

and Engineering
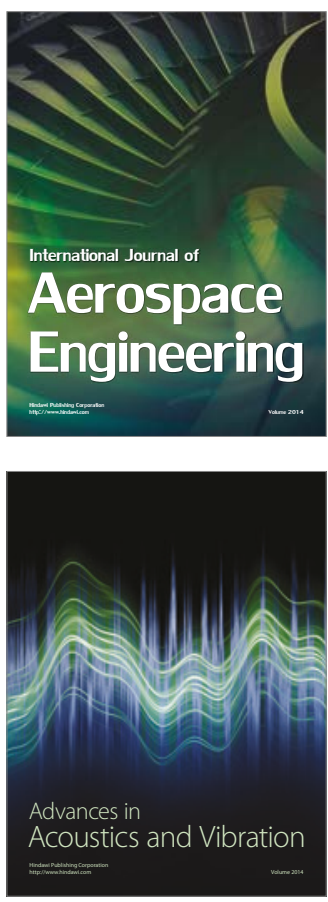

Sensor Networks 